RESEARCH PAPER RP1248

Part of Journal of Research of the National Bureau of Standards, Volume 23, October 1939

\title{
SEPARATION AND COLORIMETRIC DETERMINATION OF RHENIUM AND MOLYBDENUM*
}

\author{
By James I. Hoffman and G. E. F. Lundell
}

\section{ABSTRACT}

The method herein presented for the separation and colorimetric determination of rhenium and molybdenum depends on differential reduction with mercury. If a dilute hydrochloric acid solution containing molybdate and perrhenate is shaken with mercury, potassium thiocyanate, and ethyl ether, only the molybdenum is reduced to the form which produces an ether-soluble colored compound with thiocyanate. The color of the ether extract serves for the determination of molybdenum. Addition of stannous chloride to the acid solution remaining after the molybdenum has been extracted produces a yellow to yellowish-red ethersoluble compound which serves for the determination of rhenium. As little as $0.001 \mathrm{mg}$ of rhenium can be detected in a solution containing $10 \mathrm{mg}$ of molybdenum, and $0.01 \mathrm{mg}$ of molybdenum can be detected in the presence of $10 \mathrm{mg}$ of rhenium. Few elements interfere in the determination of rhenium, and practically all of these can be eliminated by a simple distillation.

\section{CONTENTS}

I. General considerations and preliminary experiments _... 497

II. Procedure _._.

1. Diagrammatic outline of procedure

2. Partial separation of rhenium and molybdenum from each

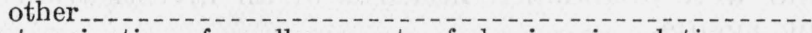

3. Determination of small amounts of rhenium in solutions containing relatively large amounts of molybdenum ..........

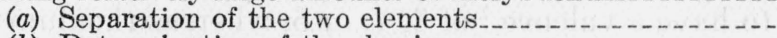

(b) Determination of the rhenium ................

(c) Determination of the molybdenum

4. Determination of small amounts of molybdenum in solutions containing relatively large amounts of rhenium ...........

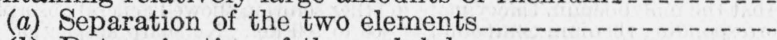

(b) Determination of the molybdenum ...............

(c) Determination of the rhenium

III. Discussion of the method.

2. Application of the procedures

3 . Stability of the colored compounds of rhenium and molyb-

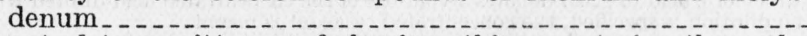

4. Spectral transmittancy of rhenium thiocyanate in ether solution (Beer's law)

5. Choice of solvents for extraction... 507

\section{GENERAL CONSIDERATIONS AND PRELIMINARY EXPERIMENTS}

In a study of the volatilization of metallic compounds, ${ }^{1}$ it became necessary to determine small amounts of rhenium in the presence of

\footnotetext{
* Originally presented by James I. Hoffman before the American Chemical Society, Boston Mass., September 15, 1939.

1 James I. Hoffman and G. E. F. Lundell, Volatilization of metallic compounds from solutions in perchloric or sulfuric acid, J. Research NBS 22, 469 (1939) RP1198.
} 
molybdenum. Each element, if it occurs alone, can be determined by using the colored solution produced by the addition of thiocyanate and stannous chloride; but if the two occur in the same solution, the method fails. ${ }^{2}$ Rhenium produces a solution which is more yellowish than the amber to cherry-red solution produced by molybdenum under the same conditions; however, experiments showed that the absorption of light by these solutions is so nearly in the same region of the spectrum that the two cannot be readily differentiated, even with the aid of filters. ${ }^{3}$

The method whereby molybdenum is converted to a xanthate complex and then extracted with chloroform ${ }^{4}$ failed to give good results, because part of the molybdenum was converted to a blue compound which could not be extracted with chloroform.

If a solution containing molybdate and perrhenate in diluted hydrochloric acid $(1+1)^{5}$ is shaken with ethyl ether, most of the molybdenum passes into the ether and most of the rhenium remains in the acid. An extraction with ether, therefore, may be used to effect a partial separation; but for final determination a sharper separation is necessary. It should be noted that the thiocyanate which each element forms after controlled reduction is completely extracted by ethyl ether.

Differences in the stability of the thiocyanates toward the action of fluorides or hydrogen peroxide were noted, but these differences are not sufficient to permit the determination of one element without interference by the other. Molybdenum thiocyanate is bleached more rapidly by peroxides or by fluorides than is the corresponding compound of rhenium. The action of fluorides is so nearly selective that a considerable amount of experimental work was done before it was decided that this method would not be satisfactory. ${ }^{6}$ Attempts of this kind were abandoned in favor of an investigation of selective reducing agents.

The molybdenum in the colored thiocyanate compound is variously stated to have a valence ${ }^{7}$ of 3,4 , or 5 , whereas rhenium in the colored compound which it forms with thiocyanate probably has a valence ${ }^{8}$

\footnotetext{
2 W. Geilmann, F. W. Wrigge, and F. Weibke, Z. anorg. allgem. Chem. 208, 217 (1932).

${ }^{3}$ In preliminary experiments, spectrographs by C. J. Rodden, of the National Bureau of Standards, indicated that the molybdenum thiocyanate in ether solution showed general absorption at 400 to $520 \mathrm{~m} \mu$, and the corresponding rhenium compound at 400 to $500 \mathrm{~m} \mu$. No sharp absorption bands were noted in either case. For comparisons of solutions containing either element alone, it was therefore found convenient in much of this work to use a Wratten filter No. 45, with transmission from 430 to $540 \mathrm{~m} \mu$, in conjunction with a photoelectric comparator (or colorimeter). The Wratten filter No. $47 \mathrm{~A}$, with transmission between 380 and $520 \mathrm{~m} \mu$, would probably have been more satisfactory. The circuit was that of B. A. Brice, Rev. Sci. Inst. 8, 279 (1937).

This method was tentatively suggested by L. C. Hurd, Ind. Eng. Chem., Anal. Ed. 8, 15 (1936).

5 This denotes 1 volume of concentrated hydrochloric acid (sp gr 1.18) diluted with 1 volume of water. Diluted hydrochloric acid $(3+200)$ denotes 3 volumes of the concentrated acid diluted with 200 volumes of water. If no dilution is specified, the concentrated reageant is meant.

${ }_{6}$ In a private communication, Loren $\mathrm{C}$. Hurd stated that he independently came to the same conclusion concerning the action of fluorides.

7 Latimer and Hildebrand, in Reference Book of Inorganic Chemistry, p. 289 (The Macmillan Co., New York, N. Y., 1933), give MoO(CNS) 3 as the formula of the colored compound of molybdenum. B. S. Hopkins, in Chemistry of the Rarer Elements, p. 260 (D. C. Heath \& Co.. New York, N. Y., 1923), gives $\mathrm{Mo}_{\mathrm{CNS}}$ as $_{\mathrm{C}}$ its formula. Feigl, in Qualitative Analyse mit Hilfe von Tüpfelreaktionen, p. 175 (Äkademische Verlagsgesellschaft, m. b. H., Leipzig, 1931), states that the molybdenum in the complex is trivalent

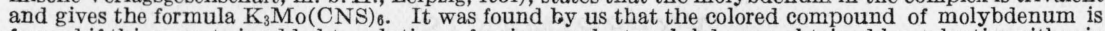
formed if thiocyanate is added to solutions of quinquevalent molybdenum obtained by reduction either in the silver reductor by the method of N. Birnbaum and G. H. Walden (J. Am. Chem. Soc. 60, 64 (1938)) or with hydriodic acid by the method of F. A. Gooch and C. Fairbanks (Am. J. Sci. (4), 6, 168 (1898)). No color is produced if sexivalent molybdenum is treated with potassium thiocyanate alone, nor if it is reduced to the trivalent state in the Jones reductor, and the solution is allowed to flow into a solution of potassium thiocyanate, in the absence of oxygen. However, if the mixture is exposed to the air for some time, a slight color gradually appears, probably because of gradual oxidation of the molybdenum. These experiments indicate that molybdenum in the colored thiocyanate compound is quinquevalent. See also Studies of the Reducing Action of Mercury, by N. H. Furman and W. M. Murray, Jr., J. Am. Chem. Soc. 58, 1689 (1936).

8 Ind. Eng. Chem., Anal. Ed. 8, 112 (1936).
} 
of 6. L. C. Hurd and B. J. Babler give $\mathrm{ReO}(\mathrm{CNS})_{4}$ as its formula. The object was to find a reagent that would reduce one of the two so that it would form the colored compound with thiocyanate, without affecting the other. Considerations of the electrode potentials, as well as actual trial, indicated that zinc, sulfur dioxide, chromous sulfate, titanous chloride, arsenious acid, and hydrazine were unsatisfactory. Rhenium is not reduced in the silver reductor under the conditions prescribed for molybdenum, but mercury seemed more convenient for effecting this differential reduction. It was finally found that if a dilute hydrochloric acid solution of molybdenum is shaken with mercury, the molybdenum is reduced to the valence required for the formation of the colored compound, but the rhenium is not affected. Moreover, it was found that, after extracting the molybdenum with ether, the rhenium can be determined with thiocyanate and stannous chloride in the usual way.

Rhenium is not reduced by mercury in $0.17 \mathrm{~N}$ hydrochloric acid (approximately $3+200$ ); but then molybdenum, if present in large amount, tends to produce a blue compound which does not react with thiocyanate. In $2.2 N$ hydrochloric acid (approximately $1+4$ ), the blue compound of molybdenum is not formed, but a trace of rhenium may be reduced and yield a color with thiocyanate. Two procedures are therefore given. In the one, the more dilute acid $(3+200)$ is used for determining small amounts of molybdenum in the presence of relatively large amounts of rhenium; in the other, the more concentrated acid is used in the separation of small amounts of rhenium from large amounts of molybdenum. It was found that better extraction of molybdenum occurs in the presence of ferric iron. A little ferric chloride is therefore always added before reduction and extraction are started.

The essential steps of the method, together with modifications for different conditions, are given in the diagrammatic outline which follows.

\section{PROCEDURE}

\section{DIAGRAMMATIC OUTLINE OF PROCEDURE}

In this outline, table 1, minor details, such as the additions of small quantities of iron and the washing of ether extracts with dilute acid, are omitted in the interest of clearness and brevity. For full details of the procedures, the reader is referred to the complete directions in the text.

\section{PARTIAL SEPARATION OF RHENIUM AND MOLYBDENUM FROM EACH OTHER}

To a solution of the two elements in 10 to $20 \mathrm{ml}$ of diluted hydrochloric acid $(1+1)$ add a slight excess of a saturated solution of potassium permanganate to make sure that the molybdenum and rhenium are present as molybdate and perrhenate, respectively. Add about $10 \mathrm{mg}$ of iron as ferric chloride, and transfer the cool hydrochloric acid solution to a separatory funnel. Add $20 \mathrm{ml}$ of ether, stopper tightly with a cork, and shake thoroughly for about 1 minute. Allow the ether and acid to separate into layers and drain the acid solution into another separatory funnel. Reserve the ether, which contains most of the molybdenum. Repeat the extraction with ether twice, adding $10 \mathrm{ml}$ of ether to the acid solution each time. Reserve the 
TABLE 1.-Diagrammatic outline of the procedure for the separation and colorimetric determination of rhenium and molybdenum

Extract with ethyl ether (repeat twice)

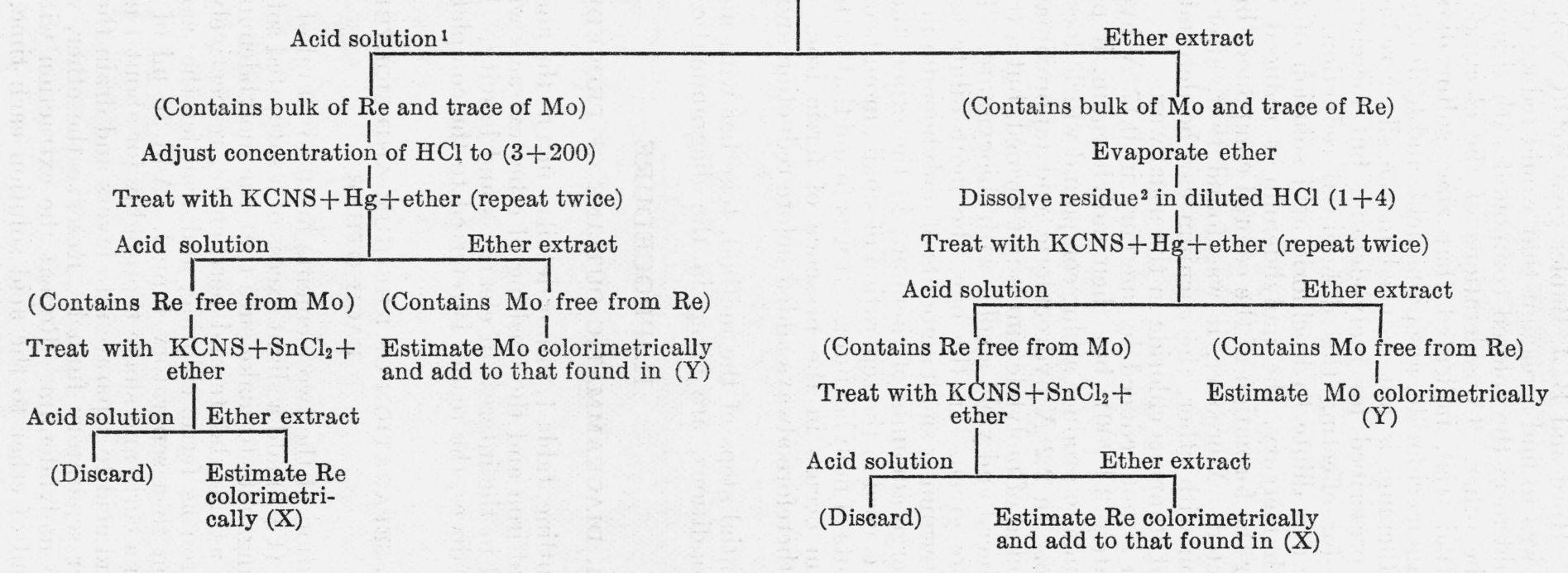

1From this point the outline corresponds with section II, 4, p. 504, "Determination of small amounts of molybdenum in solutions containing relatively large amounts of rhenium." 2 From this point the outline corresponds with section II, 3, p. 501, "Determination of small amounts of rhenium in solutions containing relatively large amounts of molybdenum." 
acid solution. Combine the three ether extracts, add $10 \mathrm{ml}$ of diluted hydrochloric acid $(1+1)$, and shake vigorously for a few seconds. When the ether and acid have separated, draw off the acid and combine it with the reserved acid solution. Reserve the ether extract, which contains the bulk of the molybdenum and a trace of rhenium. Evaporate the combined acid solutions (which contain practically all the rhenium and a trace of molybdenum) nearly to dryness on the steambath and proceed as in II, 4, p. 504, "Determination of small amounts of molybdenum in solutions containing relatively large amounts of rhenium."

Cautiously evaporate the ether extract and proceed as in II, 3, p. 501, "Determination of small amounts of rhenium in solutions containing relatively large amounts of molybdenum."

The following examples indicate the separation that can be effected by this simple ether extraction of a solution containing the elements as perrhenate and molybdate, respectively. In a separation involving $2 \mathrm{mg}$ each of rhenium and molybdenum, $0.12 \mathrm{mg}$ of rhenium was found with the molybdenum in the ether extract and $0.09 \mathrm{mg}$ of molybdenum remained with the rhenium in the acid extract. In a similar separation involving $10 \mathrm{mg}$ of each element, $0.29 \mathrm{mg}$ of rhenium was found with the molybdenum and $0.8 \mathrm{mg}$ of molybdenum remained with the rhenium.

\section{DETERMINATION OF SMALL AMOUNTS OF RHENIUM IN SOLUTIONS CONTAINING RELATIVELY LARGE AMOUNTS OF MOLYBDENUM}

This procedure is applicable to solutions containing as much as 10 $\mathrm{mg}$ of molybdenum and not more than $1 \mathrm{mg}$ of rhenium.

(a) SEPARATION OF THE TWO ELEMENTS

Add about $10 \mathrm{mg}$ of iron as ferric chloride (if this amount of iron is not already present) and a drop or two of a saturated solution of potassium permanganate to the dry or nearly dry residue containing the rhenium and molybdenum. Then add a slight excess of ammonium hydroxide and heat for a few minutes on the steam bath to make certain that the elements are present as perrhenate and molybdate, respectively. Dissolve the residue in $25 \mathrm{ml}$ of cool diluted hydrochloric acid $(1+4)$ and add $2 \mathrm{ml}$ of a 20 -percent solution of potassium thiocyanate. ${ }^{9}$ Transfer the solution to a separatory funnel containing about $25 \mathrm{~g}$ of mercury. Immediately add $20 \mathrm{ml}$ of ether, stopper the funnel tightly with a cork, and shake vigorously until the acid solution above the mercury is colorless. ${ }^{10}$ One minute of vigorous shaking usually suffices. As soon as the ether and acid have separated into layers, allow the mercury and acid to flow into another separatory funnel. Reserve the ether extract, which contains the bulk of the molybdenum.

To the separatory funnel containing the acid solution and the mercury, add $1 \mathrm{ml}$ of a 20-percent solution of potassium thiocyanate and $15 \mathrm{ml}$ of ether. Shake vigorously for 1 minute, allow the ether

\footnotetext{
- The residue sometimes dissolves with difficulty, but it goes into solution quite readily when the thiocyanate is added.

10 If elements such as chromium, vanadium, cobalt, or nickel are present, the acid solution will have the color produced by these elements, but the shaking need be continued only until it is certain that the color of the ferric thiocyanate has disappeared. 
to separate, and draw off the mercury and the acid layer as before. Reserve the ether extract.

Again add $1 \mathrm{ml}$ of a 20 -percent solution of potassium thiocyanate and $15 \mathrm{ml}$ of ether to the funnel which contains the acid solution and the mercury. Shake vigorously, and allow the ether and acid to separate into layers. ${ }^{11}$ Allow the mercury to run into a separatory funnel, and set it aside for use in future determinations. Next withdraw the acid layer which contains the rhenium ${ }^{12}$ (solution $A$ ). Reserve the ether extract, and combine it with those previously obtained (solution $B$ ).

\section{(b) DETERMINATION OF THE RHENIUM}

To determine the rhenium, add $1 \mathrm{ml}$ of a 20-percent solution of potassium thiocyanate and $1 \mathrm{ml}$ of a solution of stannous chloride ${ }^{13}$ to acid solution $A$, shake slightly, and allow to stand for 5 minutes. Add $20 \mathrm{ml}$ of ether, shake vigorously, and allow the ether and acid to separate into layers. Allow the acid to drain into another separatory funnel, and twice repeat the extraction with ether, using 15 $\mathrm{ml}$ each time. Discard the acid solution. Combine the ether extracts, add $10 \mathrm{ml}$ of diluted hydrochloric acid $(1+4)$, shake vigorously, and then allow the ether and acid to separate into layers. Withdraw and discard the acid. This acid washing removes iron, which, if allowed to remain, gradually oxidizes and produces a pink color. Transfer the ether, which contains the rhenium, to a $50-\mathrm{ml}$ flask, dilute to the mark with specially prepared ether, ${ }^{14}$ and stopper tightly. Estimate the rhenium by comparing the color with that of a standard or set of standards prepared as follows: Transfer a suitable portion of a standard solution of rhenium ${ }^{15}$ to a separatory funnel which contains $10 \mathrm{mg}$ of iron as ferric chloride and $25 \mathrm{ml}$ of diluted hydrochloric acid $(1+4)$. Then add $2 \mathrm{ml}$ of a 20 -percent solution of potassium thiocyanate and $1 \mathrm{ml}$ of stannous chloride solution. Shake slightly, allow to stand for 5 minutes, and proceed with the extraction of the rhenium and dilution of the combined ether extracts to exact volume, as was described for the solution under analysis. Typical results obtained in this determination are shown in table 2.

In the work involving less than $0.1 \mathrm{mg}$ of rhenium, only one extraction with $20 \mathrm{ml}$ of ether was made, and a series of standards was prepared which ranged from 0.01 to $0.10 \mathrm{mg}$ at intervals of $0.01 \mathrm{mg}$. By using similar $30-\mathrm{ml}$ test tubes and the same volume of ether $(20 \mathrm{ml})$, the rhenium in the unknown could be estimated by direct observation, with the line of vision at right angles to the tubes. Differences of $0.01 \mathrm{mg}$ can easily be distinguished in this way if there is less than $0.10 \mathrm{mg}$ of rhenium in $20 \mathrm{ml}$ of ether; but for concentrations greater

\footnotetext{
11 If the ether layer at this point has no appreciable color, the extraction of molybdenum is complete. A distinct color in the ether indicates that another extraction should be made.

13 From 1 to 5 percent of the rhenium passes into the ether during these extractions, but it is better to disregard this than to run the risk of extracting a trace of molybdenum and counting it as rhenium. Actually, the loss of rhenium here is without significance, because the total amount originally involved in this extraction seldom exceeds $0.5 \mathrm{mg}$. Tests have shown that the loss is proportional to the total amount of rhenium, and is not a fixed quantity.

13 Dissolve $350 \mathrm{~g}$ of $\mathrm{SnCl}_{2} .2 \mathrm{H}_{2} \mathrm{O}$ in $200 \mathrm{ml}$ of diluted hydrochloric acid $(1+1)$. Dilute the cool solution to 1 liter with cold recently boiled water.

${ }_{14}$ To prepare ether for diluting stronger ethereal solutions of molybdenum or rhenium, transfer $25 \mathrm{ml}$ of diluted hydrochloric acid $(1+4), 2 \mathrm{ml}$ of a 20 -percent solution of potassium thiocyanate, and about $10 \mathrm{~g} \mathrm{of}$ mercury to a large separatory funnel. Add 100 to $200 \mathrm{ml}$ of ether, and shake vigorously for 1 minute. Allow the ether and acid to separate, and withdraw the mercury and acid. The ether is ready for use.

15 Prepare a slightly acid solution containing $0.1 \mathrm{mg}$ of rhenium in $1 \mathrm{ml}$. If a good grade of potassium perrhenate is available, this can be done by dissolving $0.155 \mathrm{~g}$ of the salt (KReO 4$)$ in 1 liter of diluted sulfuric acid $(1+99)$. For determining less than $0.1 \mathrm{mg}$ of rhenium, it is convenient to dilute this solution to contain only $0.01 \mathrm{mg}$ in $1 \mathrm{ml}$.
} 
than $0.1 \mathrm{mg}$ in $20 \mathrm{ml}$ of ether, some form of colorimeter is necessary. If less than $0.01 \mathrm{mg}$ is present, it is preferable to make the comparisons in Nessler tubes in the usual way, in a volume not exceeding $20 \mathrm{ml}$. Dilution of aliquot portions of more concentrated solutions of rhenium in ether yields fairly satisfactory standards for determination of small amounts of rhenium; but in this, as well as in the colorimetric determination of molybdenum, the best results are obtained if the quantity of standard is so chosen that but little dilution is necessary after the color has been developed.

TABLE 2.-Results obtained in the determination of small amounts of rhenium in the presence of relatively large amounts of molybdenum

\begin{tabular}{|c|c|c|}
\hline $\begin{array}{c}\text { Rhenium } \\
\text { present }\end{array}$ & $\begin{array}{c}\text { Rhenium } \\
\text { found }\end{array}$ & $\begin{array}{c}\text { Molybdenum } \\
\text { present }\end{array}$ \\
\cline { 1 - 2 }$m g$ & $m g$ & $m g$ \\
0.0010 & 0.0009 & 10 \\
.0050 & .0048 & 10 \\
.0100 & .0109 & 10 \\
.080 & .078 & 5 \\
.100 & .097 & 10 \\
1.07 & 1.10 & 10 \\
\hline
\end{tabular}

\section{(c) DETERMINATION OF THE MOLYBDENUM}

To determine the molybdenum, transfer the combined ether extracts (solution $B$, p. 502) to a separatory funnel, and add $10 \mathrm{ml}$ of diluted hydrochloric acid $(1+4)$. Shake vigorously; then allow the ether and acid to separate into layers. Withdraw and discard the acid. Then transfer the ether solution to a 100 - or 200 -ml volumetric flask, and dilute to the mark with specially treated ether. Mix thoroughly, and compare the color with that obtained by treating a standard solution of molybdenum ${ }^{16}$ exactly as the solution under analysis was treated. The colorimetric comparison should be made without delay, because the color fades appreciably within two or three hours.

Because the standard solution may contain reduced molybdenum, the portion taken should always be heated with an excess of potassium permanganate before it is used. (See p. 499.) The addition of iron at the start must not be omitted, and the color must be developed by shaking with mercury as directed; otherwise, a slightly different color may be obtained.

In determining amounts of molybdenum between $1 \mathrm{mg}$ and $10 \mathrm{mg}$, it has been found convenient first to develop the color in a 5-mg portion of the standard solution and then to dilute the combined ether extracts obtained from the standard to $100 \mathrm{ml}$ in a volumetric flask. If the color of the solution under analysis appears to be lighter than the standard, dilution to $100 \mathrm{ml}$ is satisfactory; but if it is darker, the solution in which the molybdenum is to be determined must be diluted to $200 \mathrm{ml}$, because a concentration of $0.05 \mathrm{mg}$ of molybdenum in $1 \mathrm{ml}$ is close to the upper limit at which satisfactory comparisons of color can be made.

\footnotetext{
16 To prepare the standard solution of molybdenum, dissolve $1.5 \mathrm{~g}$ of pure sodium molybdate, $\mathrm{Na}_{2} \mathrm{MoO}_{4}$. $2 \mathrm{H}_{2} \mathrm{O}$, in $1,000 \mathrm{ml}$ of water containing $5 \mathrm{ml}$ of sulfuric acid. Standardize by reducing $50 \mathrm{ml}$ of the solution in a Jones reductor and titrating with a standard solution of potassium permanganate. (See G. E. F. Lundell, J. I. Hoffman, and H. A. Bright, Chemical Analysis of Iron and Steel, p. 319 and 325, J. Wiley \& Sons, New York, N. Y., 1931 ed.).
} 


\section{DETERMINATION OF SMALI AMOUNTS OF MOLYBDENUM IN SOLUTIONS CONTAINING RELATIVELY LARGE AMOUNTS OF RHENIUM}

This procedure is applicable to solutions containing as much as $10 \mathrm{mg}$ of rhenium and not more than $1 \mathrm{mg}$ of molybdenum.

\section{(a) SEPARATION OF THE TWO ELEMENTS}

Proceed exactly as in "Determination of small amounts of rhenium in solutions containing relatively large amounts of molybdenum" section II, 3, p. 501, but use diluted hydrochloric acid $(3+200)$ instead of $(1+4)$. The addition of iron and the treatment with permanganate at the start should not be omitted with the solution being analyzed nor in developing the color in the standard. Reserve the acid solution for the determination of the bulk of the rhenium (solution $C$ ).

\section{(b) DETERMINATION OF THE MOLYBDENUM}

Combine the ether extracts, which contain the molybdenum, and shake with $10 \mathrm{ml}$ of diluted hydrochloric acid $(1+4)$. Withdraw and discard the acid. Transfer the ether to a 50-ml Nessler tube or volumetric flask, dilute to exactly $50 \mathrm{ml}$ with specially treated ether (see footnote 14), and stopper tightly with a cork. Without delay, compare the color with that obtained by treating a known amount of molybdenum exactly as the solution under analysis was treated.

The comparison of colors may be made with a colorimeter or in Nessler tubes. The best results are obtained if solutions containing nearly the same concentrations of molybdenum are compared. If a standard containing a small quantity of molybdenum (say $0.02 \mathrm{mg}$ ) is desired, it is better to develop the color in a solution containing this amount than to dilute a small aliquot portion of an ether extract having a high concentration of molybdenum. Typical results obtained in this determination are shown in table 3.

TABLE 3.-Results obtained in the determination of small amounts of molybdenum in the presence of relatively large amounts of rhenium

\begin{tabular}{|c|c|c|}
\hline $\begin{array}{c}\text { Molybdenum } \\
\text { present }\end{array}$ & $\begin{array}{c}\text { Molybdenum } \\
\text { found }\end{array}$ & $\begin{array}{c}\text { Rhenium } \\
\text { present }\end{array}$ \\
\hline$m g$ & $m g$ & $m g$ \\
0.010 & 0.013 & 10 \\
.020 & .021 & 10 \\
.040 & .038 & 10 \\
.100 & .102 & 5 \\
.200 & .205 & 10 \\
.400 & .408 & 10 \\
.500 & .495 & 10 \\
1.00 & .97 & 10 \\
\hline
\end{tabular}

(c) DETERMINATION OF THE RHENIUM

Transfer the acid solution (solution $C$ ) to a 200-ml volumetric flask, dilute to the mark with water, and mix thoroughly. Withdraw a $10-\mathrm{ml}$ or a $20-\mathrm{ml}$ portion, and add $5 \mathrm{ml}$ of concentrated hydrochloric acid and about $10 \mathrm{mg}$ of iron as ferric chloride. If necessary, adjust the volume to $25 \mathrm{ml}$ by adding water. Then proceed with the addition of potassium thiocyanate and stannous chloride as described under "Determination of rhenium" (section II, 3 (b), p. 502). 
By applying the entire procedure to a solution containing $10 \mathrm{mg}$ each of rhenium and molybdenum, the amounts of the elements indicated in the various steps of the method, after the partial separation of perrhenate and molybdate with ether (section II, 2, p. 499), were as follows:

Molybdenum in ether extract by procedure II, 3 (c), p. $503_{-} \quad \stackrel{m g}{9.45}$

Molybdenum in acid solution by procedure II, 4, p. $504 \ldots \ldots .75$

Total molybdenum _...

Rhenium in the ether extract by procedure II, 3 (b), p. 502 $\quad .29$

Rhenium in the acid solution by procedure II, 4 (c), p. 504_ 9.68

Total rhenium_............ 9. 9. 97

\section{DISCUSSION OF THE METHOD}

\section{INTERFERING ELEMENTS}

Unless otherwise stated, the tests for interferences by other elements were made by treating $2 \mathrm{mg}$ of the element as if determinations of rhenium and molybdenum were being made.

Cerium, cobalt, chromium, gallium, germanium, indium, iridium, lead, nickel, osmium, ruthenium, thallium, and uranium showed no interference. By increasing the amount of chromium to $40 \mathrm{mg}$, a slight green tint was imparted to the ether, which interfered in the determination of both rhenium and molybdenum.

Platinum and rhodium interfere because they impart colors where rhenium or molybdenum should be indicated. Furthermore, they separate as the metals and thereby contaminate the mercury.

Vanadium interferes in the determination of molybdenum by imparting a color, but it does not interfere in the determination of rhenium. The interference is not serious. With $2 \mathrm{mg}$ of vanadium, a color equivalent to only $0.01 \mathrm{mg}$ of molybdenum was indicated.

Tungsten interferes by imparting a greenish-yellow tint to the ether where rhenium or molybdenum should appear.

Copper, gold, palladium, selenium, and tellurium do not impart colors to the ether, but they separate and contaminate the mercury. The presence of small amounts of these elements does not prevent the determination, but new mercury would probably be required for each analysis.

No tests were made with elements not mentioned above, but there is no reason to believe that any of them would produce colored solutions that would be extracted by ether.

\section{APPLICATION OF THE PROCEDURES}

Only in rare instances would it be necessary to use the whole procedure as given. The method was developed primarily to determine small amounts of the one element in the presence of relatively large amounts of the other. Usually, previous information concerning the material to be analyzed will permit the omission of the first part, II, 2, p. 499, "Partial Separation of Rhenium and Molybdenum from each other." More than likely only a trace of the one element in the presence of a relatively large amount of the other is to be determined. In such a case, the analyst can conveniently start with II, 3, p. 501, "Determination of small amounts of rhenium in solutions containing 
relatively large amounts of molybdenum" or with II, 4, p. 504, "Determination of small amounts of molybdenum in solutions containing relatively large amounts of rhenium," whichever suits the particular material. If large amounts of both elements are present, other methods are more suitable than the colorimetric ones described herein, as for example, the methods using $a$-benzoinoxime ${ }^{17}$ for molybdenum, or nitron ${ }^{18}$ for rhenium.

The procedure is especially suitable for determining small amounts of rhenium in distillates obtained when solutions containing sulfuric or perchloric acid, together with hydrochloric or hydrobromic acid, are boiled. With the possible exception of chromium, such distillates contain no elements that interfere in the determination of rhenium; ${ }^{19}$ but, in order to obtain a small volume and the proper concentration of acid, the rhenium in these distillates is best precipitated with hydrogen sulfide and then converted to perrhenate before the colorimetric determination is attempted. In testing such a procedure, small amounts of rhenium were transferred to a distilling flask containing hydrochloric and perchloric acids. The rhenium was then distilled by the procedure just mentioned. Small amounts of molybdenum were added to the distillate to simulate a solution which might be obtained by distilling rhenium from a material high in molybdenum. The solution, $100 \mathrm{ml}$ in volume, was neutralized with ammonium hydroxide, $3 \mathrm{ml}$ of sulfuric acid and $5 \mathrm{mg}$ of trivalent arsenic (to act as a gatherer) were added, and the solution was saturated with hydrogen sulfide. After the solution had stood overnight, the sulfides were gathered on a small filter, and, without washing, were dissolved in ammonium hydroxide containing hydrogen peroxide. After evaporating the solution to dryness, the rhenium and molybdenum were determined by procedure II, 3, p. 501. Two trial analyses were made. In one, $0.010 \mathrm{mg}$ of rhenium was added to the distilling flask and $0.020 \mathrm{mg}$ of molybdenum to the distillate. The rhenium and molybdenum found were respectively $0.009 \mathrm{mg}$ and $0.021 \mathrm{mg}$. In a similar analysis involving 0.005 $\mathrm{mg}$ of rhenium and $0.20 \mathrm{mg}$ of molybdenum, $0.0045 \mathrm{mg}$ of rhenium and $0.20 \mathrm{mg}$ of molybdenum were found.

\section{STABILITY OF THE COLORED COMPOUNDS OF RHENIUM AND MOLYBDENUM}

Under the conditions outlined in the foregoing procedures, the color of molybdenum thiocyanate fades fairly rapidly. Comparisons should therefore be made as soon as possible (preferably within 1 hour) after the compound has been extracted. The color of the rhenium compound is rather stable. In observations made with the photoelectric colorimeter mentioned in footnote 3, p. 498, it was found that a standard containing $0.5 \mathrm{mg}$ of rhenium in $50 \mathrm{ml}$ of ether changed only about 3 percent in 4 days. The measurements at the single wave length of $435.8 \mathrm{~m} \mu$, described in the next section, showed that a solution 0.576 $\times 10^{-5}$ molar with respect to rhenium (1.0736 mg/liter) faded about 2.5 percent in 2 days, whereas one that was $2.9 \times 10^{-5}$ molar $(5.368$

${ }_{17}$ H. B. Knowles, BS J. Research 91 (1932) RP453.

18 W. Geilmann und F. Weibke, Z. anorg. allgem. Chem. 195, 289 (1931).

10 See the tabulation on p. 467 of Volatilization of Metallic Compounds from Solutions in Perchloric or Sulfuric Acid, J. Research NBS 22 (1939) RP1198. 
$\mathrm{mg} /$ liter) increased in color by 0.5 percent. It is obvious that such slight changes are not significant in the determination of small amounts of rhenium and that uncertainties caused by such changes in color disappear if the colors in the standards and the unknowns are developed at the same time. The fairly rapid fading of the color of the molybdenum compound obtained by reduction with mercury is a disadvantage and indicates that if molybdenum alone is to be determined, reduction with stannous chloride is preferable.

It should be observed that, throughout the procedure, final shaking of the ether extracts with dilute hydrochloric acid is recommended. If this is not done, gradual oxidation of the iron may cause a pink color which would result in positive errors.

\section{SPECTRAL TRANSMITTANCY OF RHENIUM THIOCYANATE IN ETHER SOLUTION (BEER'S LAW)}

Ether solutions of rhenium thiocyanate for measurements of spectral transmittancy were prepared by the procedure described for the preparation of the standards in "Determination of the rhenium" II, 3 , b, p. 502. The measurements of transmittancy were made by $\mathrm{H}$. J. Keegan, of the Colorimetry and Spectrophotometry Section of the National Bureau of Standards, with a General Electric recording spectrophotometer. ${ }^{20}$ In each case the transmission of a $1-\mathrm{cm}$ cell containing a given concentration of rhenium in ether solution was measured relative to that of a similar $1-\mathrm{cm}$ cell filled with pure ethyl ether. The curves obtained with 2-day old solutions are shown in figure 1. The color in the very dilute solutions had a tendency to fade, and the more concentrated ones (as represented by curves 12 and 13) showed lower transmittancy with increased age. Although these curves are not quite consistent with those which would be obtained if Beer's law were obeyed, they do show the type of transmittancy curve and the wave length $(432 \mathrm{~m} \mu)$ of maximum absorption.

Additional measurements of transmittancy of freshly prepared solutions were made by K. S. Gibson with the König-Martens visual spectrophotometer ${ }^{21}$ at the single wave length of mercury $(435.8 \mathrm{~m} \mu$ ). These showed a slight deviation from Beer's law, but in the opposite direction from that indicated by the previous measurements. Apparently, the slight instability of the solutions makes it impossible to state with certainty, without extensive additional measurements, whether or not the solutions obey Beer's law.

\section{CHOICE OF SOLVENTS FOR EXTRACTION}

Throughout most of this work, ethyl ether was used for extracting the colored compounds of rhenium and molybdenum. Other solvents, for instance, amyl alcohol, ethyl acetate, or butyl acetate, can probably also be used. In a few determinations fairly "satisfactory presults were obtained with butyl acetate; but if the solvent must be evaporated, ether is preferable. In the partial separation of rhenium from

20 See A. C. Hardy, J. Opt. Soc. Am. 25 (1935); J. L. Michaelson, J. Opt. Soc. Am. 28, 365 (1938); K. S. Gibson and H. J. Keegan, J. Opt. Soc. Am. 28, 372 (1938).

21 H. J. MoNicholas, BS J. Research 1, 793 (1928) RP30. 


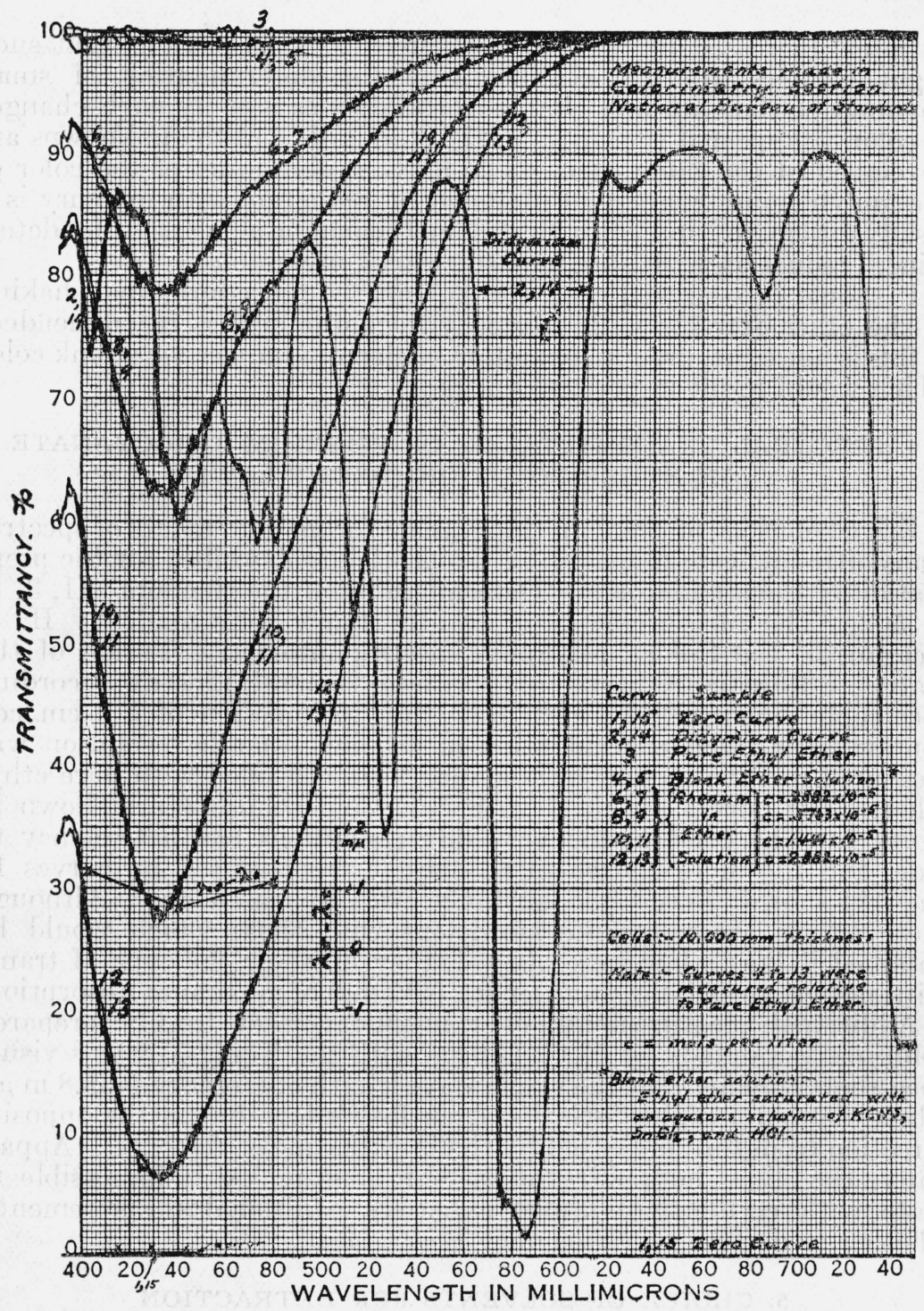

FigURE 1.-Transmittancy curves of rhenium thiocyanate solutions.

molybdenum (section II, 2, p. 499), considerably better partition was effected by ether than by butyl acetate, and the ethereal solutions usually were clearer than those obtained with butyl acetate.

Washington, July 11, 1939. 